\title{
Non-contact thermal imaging as potential tool for personalized diagnosis and prevention of cellulite
}

\author{
Joanna Bauer ${ }^{1} \cdot$ Martyna Grabarek $^{1} \cdot$ Agnieszka Migasiewicz $^{2} \cdot$ Halina Podbielska $^{1}$
}

Received: 15 August 2017 / Accepted: 31 March 2018/Published online: 7 April 2018

(C) The Author(s) 2018

\begin{abstract}
Cellulite, the problem of dimpled appearance of the skin, affects approximately $85 \%$ of female population in developed countries and is classified as one of the worst tolerated by women deteriorating their quality of life and self-esteem. There is a lack of early, objective, quantitative and personalized diagnosis of different stages of cellulite, thus making prevention or early therapeutic intervention difficult. We have demonstrated the efficacy of thermal imaging using IR thermography in a group of female volunteers with different stages of cellulite. By analyzing the superficial temperature distribution of the body, it was possible to diagnose the cellulite stage. The thermal images of posterior site of thighs were recorded, and cellulite areas were identified for further quantitative analysis. We used a custom-designed classification scheme for automatic recognition of the different stages of cellulite as per the well-known Nürnberger-Müller diagnosis scheme. It was possible to diagnose the cellulite stages with over $80 \%$ accuracy. The accuracy can be further increased to over $97 \%$ using a threshold value correction scheme. Our work has shown that IR thermography when coupled with computer-aided imaging analysis and processing can be a very convenient and effective tool to enable personalized diagnosis and preventive medicine to improve the quality of life of women with cellulite problem.
\end{abstract}

Keywords Thermal imaging · Infrared thermography $\cdot$ Cellulite $\cdot$ Skin imperfection · Personalized medicine · Preventive medicine

\section{Introduction}

Cellulite, also known as lipodystrophy, edematous fibrosclerotic panniculopathy, adiposis edematosa, dermopanniculosis deformans or status protrusus cutis, refers to as pathological changes in skin formation that is manifested in numerous cavities and irregularities in skin morphology. Cellulite can be considered to be one of the civilization diseases linked to the modern lifestyle and way of nutrition. As statistics show, the problem of lipodystrophy affects women, predominantly. The number of

Joanna Bauer

joanna.bauer@pwr.edu.pl

1 Department of Biomedical Engineering, Faculty of Fundamental Problems of Technology, Wrocław University of Science and Technology, Wrocław, Poland

2 Department of Cosmetology, Faculty of Physiotherapy, Wrocław University School of Physical Education, Wrocław, Poland women affected by cellulite is constantly increasing. More worrisome is that they become affected by cellulites at an earlier age. For example, more than $90 \%$ of women over the age of 30 have at least one of the symptoms of lipodystrophy such as edema, local microvascular disorders, abnormalities in adipose tissue structure and decreased skin and subcutaneous tissue elasticity. It is estimated that around $85 \%$ of mature women suffering from cellulite are in the developed world [1, 2].

Cellulite tends to appear more in the region of lower extremities, thighs and buttocks. It can also occur at lower abdomen, shoulders and breast. These are regions where estrogen is responsible for fat deposition [3]. The disease is accompanied by a chronic inflammatory process involving fat tissue, connective and peripheral lymphatic and blood system, as well as osteoarthritis-fibrosis degenerative materials of the subcutaneous tissues. The first symptoms of cellulite may appear as early as during adolescence and can affect about $12 \%$ of girls. The percentage of illnesses increases significantly during pregnancy by about $20 \%$ due 
to increased supply of female sex hormones. The increase in the number of cases is also observed in menopausal or perimenopausal women (nearly $25 \%$ ) due to a decline in steroid concentrations and water management disorders $[4,5]$.

Cellulite negatively affects women quality of life and self-esteem. It has been classified as one of the worst-tolerated symptoms by women [6]. As such, it attracted numerous studies related to pathophysiology [7, 8] diagnosis $[6,9,10]$ prevention and treatment through various anti-cellulite therapies [11-14]. Cellulite-specific symptoms appear as uneven, wrinkled skin surface with numerous thickenings, bulges and furrows, which represent defects and a weakening of connective tissues. The appearance of cellulite is associated with morphological, biochemical and structural changes. [15-18]. It is related to a loss in the quantity and function of dermal collagen fibers, which, in turn is connected with skin laxity, flaccidity and sagging $[19,20]$. Personalized, early stage intervention can potentially prevent the occurrence of cellulite and is one of the goals of our present study. Among the pathophysiology theories of cellulite formation, the so-called vascular theory is relevant to our study and will be discussed here.

The vascular theory of cellulite etiology classifies it as a degradation process initiated by a deterioration of the dermal vasculature. Usually cellulite starts with microcirculation disorders and stagnation within the blood vessels and lymph vessels, leading to decreased permeability. As a consequence, there is a disruption of the nutrient supply to the cells and disturbances in the discharge of unnecessary metabolic products. This, in turn results in excessive accumulation of fluid in the intercellular spaces [1,21]. The loss of the capillary networks [22] is caused by clumped fat cells (adipocytes) that inhibit venous return [23] and retain excess fluid within the dermal and subcutaneous tissues [24]. Vascular changes begin to occur within the dermis, protein synthesis decreases, and tissue self-repair is affected. Beneath the skin, protein clumps accumulate around the enlarged adipocytes. At this stage, cellulite is, however, not seen and skin still appears as smooth. These early symptoms can be only noticed when skin is pinched between the thumb and the forefinger, giving 'orange peel' appearance. In the next stage, hard reticular proteins form around fat nodules within the dermis, which is thinning while subcutaneous fat tissue protrudes. Together, they translate into characteristic for cellulite skin alterations which can be seen at surface [21].

Based on the consistency of skin, cellulite is usually classified into four general types: hard, soft, edematous and mixed. Hard cellulite occurs mainly in the slim and physically active people. It often affects teenagers or young women, whose skin is relatively tight and firm. Defects only appear during a change in body position or during a pinch test. Over time, this can transform into so-called soft cellulite, usually found in mature women with low physical activity. It is caused by hypotonia (loss of muscle mass, strength and tone) and an increase in the fat volume. Within the subcutaneous tissue, telangiectasia and microcytosis occur. Irregular beads and nodules can appear too and cause pain. This stage of cellulite is characterized by a progressive loss of elasticity, pliability and skin flaccidity $[21,25]$. Edematous cellulite is relatively rare and manifests itself with a significant increase in the volume of the lower limb tissues. The skin around the lesions is thin, pale and distinctly colder, with microcirculation disorders and local hypothermia. The patient has a severe feeling of heavy and sore legs. Characteristic for this stage is a positive result of Godet test (a dimple in the skin appearing when pinched). Statistically, mixed cellulite occurs in women most frequently. Here, one patient can have different types and stages of cellulites at different locations of the body [1].

Cellulite develops in a few overlapping stages, which can take months, and sometimes even years, to fully manifest. A number of classification schemes can be found in the literature. Table 1 depicts one of the oldest and most commonly used classification schemes proposed by Nürnberger and Müller in 1978 [26]. This classification scheme is based on palpation (Godet test) and visual evaluation of skin. It is simple and the most convenient for daily use. However, it is very subjective as it requires physical pinching of the patient and visual inspection by a trained dermatologist or cosmetologist.

Janda and Tomikowska [1] proposed in 2014 another classification scheme that also identified 4 stages of cellulite formations taking into account clinical, thermographic and histopathological changes in the skin and subcutaneous tissue. This classification, however, is more complicated and requires special equipment and very highly trained personnel for operation, thermography and dermatological analysis and diagnosis. As such it is difficult to implement in a decentralized, personalized, day-today diagnosis.

Hexsel et al. [3] have proposed a photonumeric cellulite severity scale (CSS). Five key clinical morphologic features of cellulite were identified in this scale:

A. the number of evident depressions;

B. depth of depressions;

C. morphological appearance of skin surface alterations like 'orange peel' appearance, 'cottage cheese' appearance or 'mattress' appearance;

D. grade of laxity, flaccidity or sagging skin; and

E. the classification scale originally described by Nürnberger and Müller. 
Table 1 Visual-palpation scale of cellulite progression according to Nürnberger and Müller [3, 26]

\begin{tabular}{ll}
$\begin{array}{l}\text { Cellulite } \\
\text { stage }\end{array}$ & Stage description \\
\hline 0 & Skin healthy, no alteration even during pinching \\
1 & Skin smooth in both standing and laying positions, alterations to the skin surface only visible when the skin is pinched \\
2 & $\begin{array}{l}\text { Skin irregularities (so-called orange peel or cottage cheese appearance or mattress appearance) visible in standing position } \\
\text { without pinching, in laying down position skin is smooth }\end{array}$ \\
3 & Skin irregularities visible in both standing and laying positions \\
\hline
\end{tabular}

The severity of each of above-described items is graded from 0 to 3, allowing to calculate a final sum of scores that vary from 1 to 15 . Based on the final numeric score, cellulite is further classified as mild (total score 1-5), moderate (total score 6-10) or severe (total score 11-15). This elaborate scoring scheme provides a thorough quantitative underpinning in the diagnoses although pinching of the skin may still be required to make cellulites more visible.

As it can be seen in the above examples, diagnoses and clear assessments of cellulite stages are not trivial. Alternative means of cellulite diagnosis, however, may require the use of advanced diagnostic tools and methods such as magnetic resonance imaging, computed tomography, static and dynamic elastography, contact thermography, videocapillaroscopy and classical, high frequency or Doppler ultrasonography [27]. These diagnostic tools are not always available in a typical aesthetic or cosmetic practices or dermatology centers due to high capital cost and specialized training.

Here, we demonstrate the use of non-contact thermal imaging as an alternative method for cellulite stage classification for personalized diagnosis. Contact thermography has been used for cellulite diagnosis where specialized liquid crystal mats are required to be applied to the suspect site of the body [27]. Infrared (IR) thermography, in contrast, does not require any direct contact with the patient and allows remote and non-contact assessment of the surface temperature distribution of the examined body [28, 29]. The method is widely used for superficial temperature distribution' measurements in medicine, e.g., screening tests [30], prevention [31], diagnosis [32, 33], treatment' assessment [34-36], physiotherapy [37, 38] as well as personalized medicine [39, 40].

It is completely safe for the patient because it is based on the measurement of the electromagnetic radiation in the infrared range naturally emitted from the human body itself [5, 28]. This allows obtaining information about both physiological and pathological processes in the examined part of the body. Dermatological effects such as cellulite manifest as superficial temperature changes that can be conveniently detected, quantified and machine-analyzed using IR thermography for automatic decision making. In this work, non-contact thermography has been used for an objective and quantitative assessment of different stages of cellulite.

\section{Materials and methods}

The small clinical trial involving human volunteers was conducted in conformance to the ethical guidelines of the Declaration of Helsinki following the approval of the Senate Ethics Committee for Scientific Research at the University School of Physical Education in Wrocław.

We created a database of a total of 118 thermal images at a resolution of $320 \times 240$ pixels. These images were taken under informed written consent from the female volunteers, aged 19-22 with different stages of cellulite, which had been diagnosed a priori by a licensed cosmetologist using the Nürnberger-Müller scale (Table 1). Experiment strictly followed the recommendations of European Association of Thermology for thermographic measurements in medical applications, including preparation of the volunteers, exclusion/inclusion criteria for subjects, environmental conditions and imaging system operational requirements [41].

In order to maintain constant ambient conditions, measurements were taken in one room at a specific time of the day. The air temperature was also monitored at $22-24{ }^{\circ} \mathrm{C}$, and humidity was $35-40 \%$. Before the testing, volunteers were asked to expose their thighs. Then, they were asked to stay in standing positions for $20 \mathrm{~min}$ so that they could adopt to the room conditions. No severe physical activity was performed so that the body temperature could be stabilized. Thermal images of the backside (posterior part) of thigh were recorded for each volunteer with a thermographic camera FLIR T335 operating at a spectral range of 7.5-13 $\mu \mathrm{m}$ with a temperature sensitivity of $50 \mathrm{mK}$ at $30{ }^{\circ} \mathrm{C}$. Images were taken at a fixed distance of $1.2 \mathrm{~m}$.

All thermal images were analyzed using a ThermaCAM Researcher Pro 2.10 software, which allowed automatic normalization of the temperature distribution for all 
images. This normalization was needed because the temperature range of the originally recorded images varied slightly for which the thermal imaging camera needed to adjust automatically to find the coldest and warmest point in the analyzed area. After normalization, the lowest and highest temperatures for these images were set to the values of 20.6 and $36.2{ }^{\circ} \mathrm{C}$, respectively.

Figure 1 shows typical thermal images taken on volunteers. We assume that a non-pathological skin would provide a reasonably uniform temperature distribution in the thermal image (Fig. 1a). The cellulite in thermal images forms contours of surfaces and shapes with uneven and higher temperature than the surrounding tissues (Fig. 1b). These are the regions of microcracks and swollen blood vessels that cause thermal irregularity. Suspect cellulite areas have high heterogeneity in temperature distribution and were marked manually (Fig. 1c-e) using the ThermaCAM software, which indicated a temperature difference with respect to the surroundings.

These thermal images were then further analyzed in ImageJ software to measure parameters such as the number of cellulite irregularities and their corresponding areas in pixels (px). This made it possible to obtain quantitative parameters such as the cumulative area of cellulite spots. Four different classification parameters were tested:

- Classifier 1 Number of irregularities

- Classifier 2 Cumulative area of irregularities/px

- Classifier 3 Ratio of cumulative area of irregularities and area of thighs/px

- Classifier 4 Product of irregularities' number and area of irregularities/px

For the purpose of this study, the collected database was divided into 2 subsets: learning (59 images) and testing (59 images). This division allowed us to evaluate the recognition accuracy of the tested images for different stages of cellulite based on learning outcomes. After initial testing, the classification system was optimized using a novel optimization scheme discussed in the following section.

\section{Results and discussion}

For quantitative analysis that can be automated for personalized medicine, it is important to define parameters that will let high-quality classification of cellulite stages for an unambiguous distinction using thermal images. In the (a)

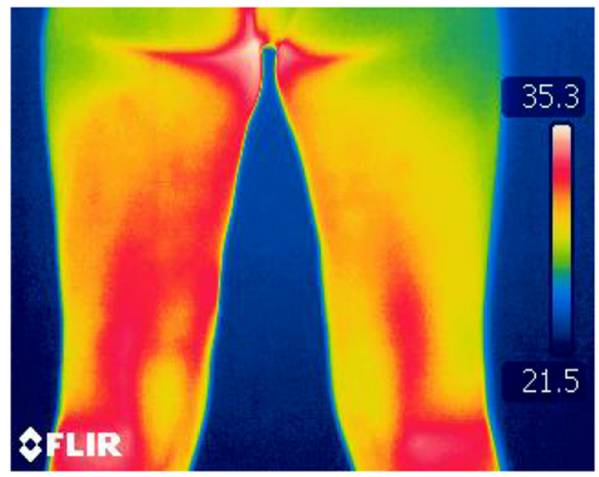

(c)

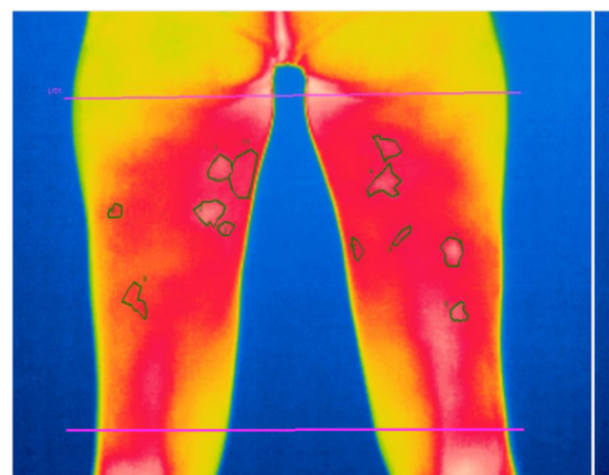

(d) (b)

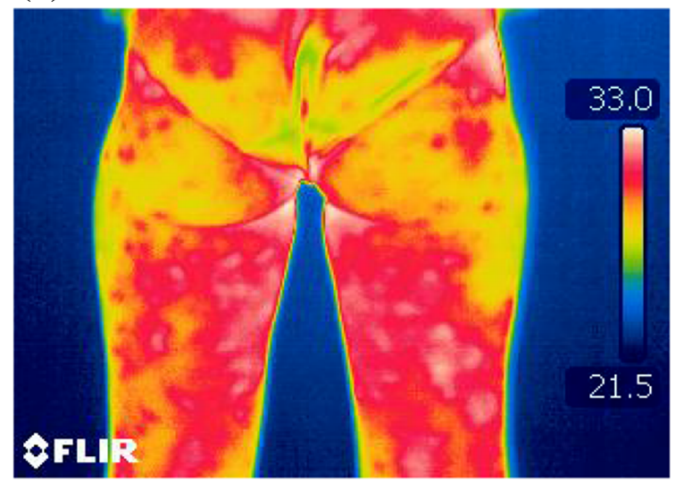

(e)

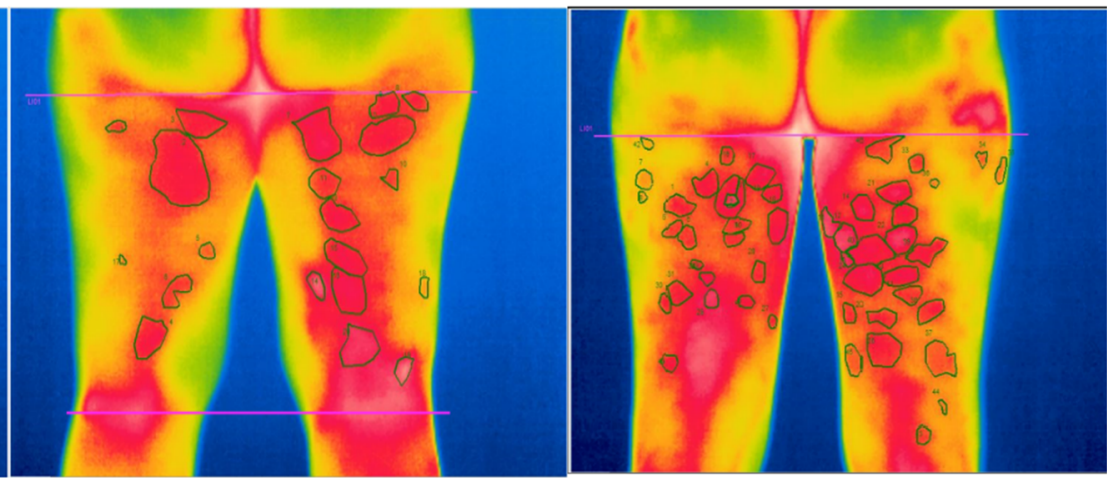

Fig. 1 Typical thermal images of thighs of a healthy volunteer (a), a volunteer with high occurrences of cellulite (b) and volunteers with cellulite of 1st stage (c), 2nd stage (d) and 3rd stage (e). Suspect areas were marked using ThermaCAM software (c-d) 
preceding section, we have defined four such parameters (classifiers). We now examine whether there is a relationship between our proposed classifiers and clinically identified different stages of cellulite. For this, we need an essential step for accepting or rejecting a particular classifier (Fig. 2a-d). This relationship would represent the dependence of individual classifiers' mean values on the respective subgroups of volunteers with different stages of clinically diagnosed cellulites (stages $0,1,2$ and 3 , Table 1). This is an acceptable starting point as the respective mean values differ for different stages of cellulite (Fig. 2a-d).

The validity of these parameters has been further tested for distinct recognition of different stages of cellulite. This has been carried out by calculating values for all four classifiers for each of the 59 images in the learning database. We then ranked these classifier values with respect to the cellulite stages to obtain a robust threshold values that can allow us easy distinctions between cellulite stages using image analysis. Table 2 shows the lower and upper limits of these values. It is acceptable that there will be some overlap between successive stages such as $0-1,1-2$, $2-3$. It is, however, not acceptable that there would be an overlap between three stages such as 1-2-3. It can be seen that Classifiers 1 and 2 were unable to distinguish between cellulite stages such cases (Table 2, cellulite stages 1-2-3). This means that the classifying powers of these two parameters are low. On the other hand, Classifiers 3 and 4 do not have such ambiguity and possess stronger classifying power. For further cellulite stage recognition, we used only Classifiers 3 and 4.

We then use images from the testing database to check whether the threshold values defined from the learning database (Table 2) allows to distinguish different stages of cellulite. Table 3 provides the accuracy of the stage assignments based on such thresholds in Classifiers 3 and 4. Clearly, Classifier 3 shows, on an average, a better ability of distinguishing different stages of cellulite (83.05 vs. $79.66 \%$ ).

We believe that the accuracy can be further improved by resorting to algorithm-based corrections, machine-based identification of cellulite and a larger population for learning database. To validate the first point, we make some corrections of the threshold value separating the particular cellulite stages as follows:

- Correction no. 1 The threshold values of classifiers' ranges were increased about $0.001 \mathrm{px}$ (Classifier 3) and 10,000 px (Classifier 4).

- Correction no. 2 The threshold values of ranges were decreased adequately by $0.001 \mathrm{px}$ (Classifier 3) and 20,000 px (Classifier 4).

The results of these corrections are listed in Table 4. We then applied another correction:
Fig. 2 Dependence of classifiers mean values on the cellulite stage for the whole analyzed population: Number of irregularities (a), cumulative area of irregularities (b), ratio of cumulative area of irregularities and area of thighs (c) and product of irregularities' number and area of irregularities (d) (a)

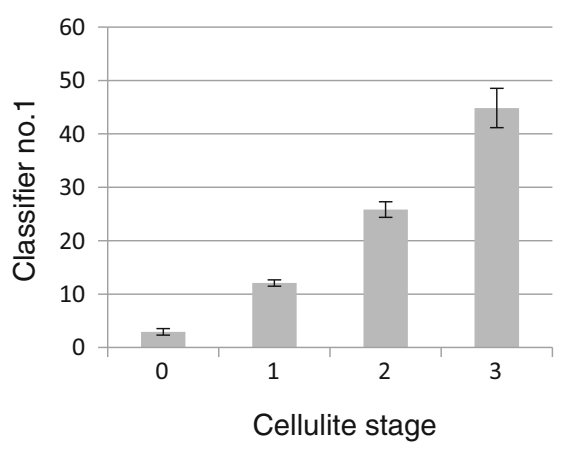

(c)

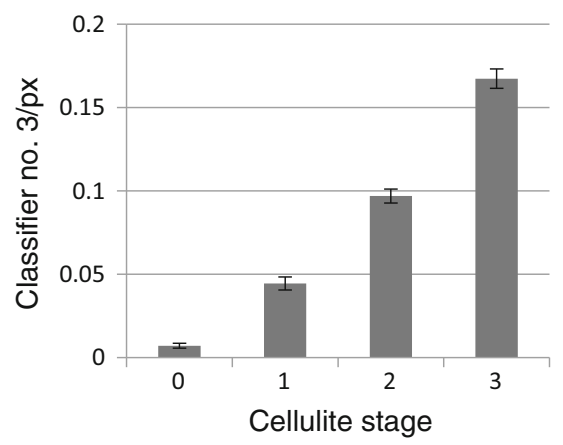

(b)

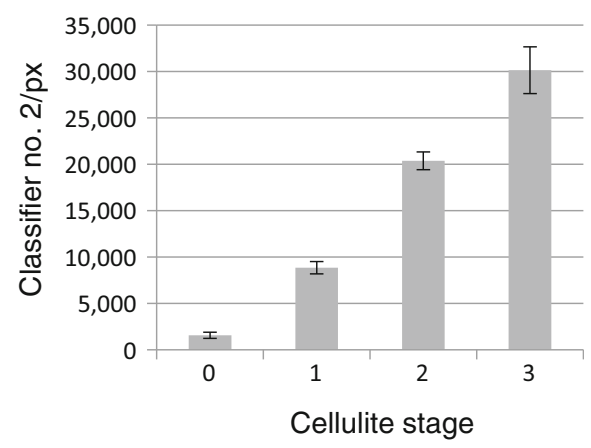

(d)

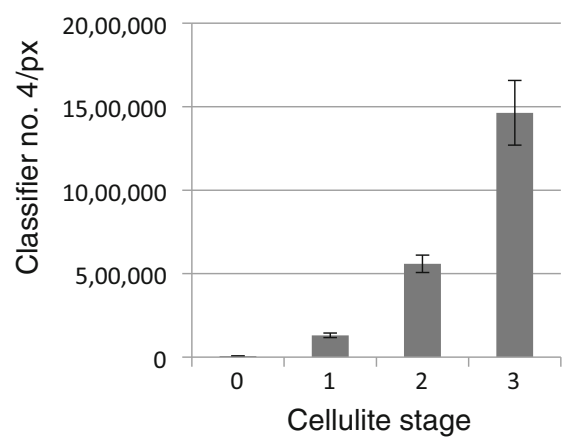


Table 2 Value ranges for four parameters that are common parts for different degrees of panniculopathy

\begin{tabular}{|c|c|c|}
\hline Classifier No & $\begin{array}{c}\text { Cellulite stage } \\
\text { as per Table } 1\end{array}$ & Range of classifiers' values/px \\
\hline \multirow{4}{*}{1} & $0-1$ & $<3,6>$ \\
\cline { 2 - 3 } & $1-2$ & $<7,16>$ \\
\cline { 2 - 3 } & $1-2-3$ & $<13,25>$ \\
\cline { 2 - 3 } & $2-3$ & $<24,48>$ \\
\hline \multirow{4}{*}{2} & $0-1$ & $<1417,3795>$ \\
\cline { 2 - 3 } & $1-2$ & $<3796,18379>$ \\
\cline { 2 - 3 } & $1-2-3$ & $<12065,26182>$ \\
\hline \multirow{4}{*}{3} & $2-3$ & $<18380,37858>$ \\
\cline { 2 - 3 } & $0-1$ & $<0.0076,0.0176>$ \\
\cline { 2 - 3 } & $1-2$ & $<0.0176,0.0983>$ \\
\hline \multirow{4}{*}{4} & $2-3$ & $<0.0597,0.1640>$ \\
\cline { 2 - 3 } & $0-1$ & $<5665,21000>$ \\
\cline { 2 - 3 } & $1-2$ & $<21001,357560>$ \\
\hline
\end{tabular}

- Correction no. 3 As a classification criterion both of Classifierss 3 and 4 were taken altogether. During this stage, we checked which of the images taken from the tested database complied with both Classifier 3 and Classifier 4 at the same time. The decision was taken only in case where the same stage of cellulite of each classifier was achieved. The images where there was a conflict between assigned stages between Classifiers 3 and 4 had been termed as undefined. The results after such corrections are given in Table 5.

The final, optimized threshold values after above corrections are given in Table 6 .

Similar to the previous study carried out by Nkengne et al. [5], our report shows that IR thermography can be used for non-contact diagnostic imaging of cellulite. The significance of our investigation is in defining a quantitative methodology of image analysis to obtain high accuracy recognition of different stages of cellulite. We have shown the feasibility of using IR thermography for automatic recognition of these stages. The accuracy can be further improved by using pattern recognition for more automated cellulite identification, algorithm-based corrections and a larger-scale clinical investigation for machine learning.

It is worth to emphasize that IR thermography provides relatively high reproducibility and low-cost diagnosis
Table 3 Efficacy of the recognition process based on the first determination of betweenclass boundaries between the cellulite stages

\begin{tabular}{|c|c|c|c|c|}
\hline $\begin{array}{l}\text { Classifier } \\
\text { No }\end{array}$ & $\begin{array}{l}\text { Cellulite } \\
\text { stage }\end{array}$ & $\begin{array}{l}\text { Total No of } \\
\text { images for the } \\
\text { stage }\end{array}$ & $\begin{array}{l}\text { No of correctly } \\
\text { recognized images }\end{array}$ & $\begin{array}{l}\text { Percentage of images classified } a^{\prime} \text { priori } \\
\text { according to Nürnberger-Müller scheme/\% }\end{array}$ \\
\hline \multirow{5}{*}{3} & 0 & 7 & 6 & 85.71 \\
\hline & 1 & 32 & 26 & 81.25 \\
\hline & 2 & 16 & 13 & 81.25 \\
\hline & 3 & 4 & 4 & 100.00 \\
\hline & In total & 59 & 49 & 83.05 \\
\hline \multirow{5}{*}{4} & 0 & 7 & 7 & 100.00 \\
\hline & 1 & 26 & 24 & 92.31 \\
\hline & 2 & 19 & 12 & 63.16 \\
\hline & 3 & 7 & 4 & 57.14 \\
\hline & In total & 59 & 47 & 79,66 \\
\hline
\end{tabular}

Table 4 Cellulite stage recognition accuracy after optimizations using correction no. 1 and correction no. 2

\begin{tabular}{|c|c|c|c|c|c|c|}
\hline \multirow{2}{*}{$\begin{array}{l}\text { Cellulite } \\
\text { stage }\end{array}$} & \multicolumn{3}{|l|}{ Classifier 3} & \multicolumn{3}{|l|}{ Classifier 4} \\
\hline & $\begin{array}{l}\text { Before } \\
\text { correction/\% }\end{array}$ & $\begin{array}{l}\text { After correction no. } \\
1 / \%\end{array}$ & $\begin{array}{l}\text { After correction no. } \\
2 / \%\end{array}$ & $\begin{array}{l}\text { Before } \\
\text { correction/\% }\end{array}$ & $\begin{array}{l}\text { After correction no. } \\
1 / \%\end{array}$ & $\begin{array}{l}\text { After correction no. } \\
2 / \%\end{array}$ \\
\hline 0 & 85.71 & 87.50 & 85.71 & 100.00 & 100.00 & 66.67 \\
\hline 1 & 81.25 & 84.38 & 83.33 & 92.31 & 92.59 & 95.65 \\
\hline 2 & 81.25 & 86.67 & 81.25 & 63.16 & 66.67 & 72.22 \\
\hline 3 & 100 & 100 & 100 & 57.14 & 57.14 & 72.22 \\
\hline Total & 87.05 & 89.64 & 87.57 & 78.15 & 79.10 & 76.69 \\
\hline
\end{tabular}


Table 5 Cellulite stage recognition accuracy after optimizations using correction no. 3

\begin{tabular}{|c|c|c|c|c|}
\hline \multirow{3}{*}{ Classifier } & Cellulite stage & No of images & $\begin{array}{c}\text { No of correctly } \\
\text { classified images }\end{array}$ & $\begin{array}{c}\text { Compatibility with } \\
\text { Nürnberger-Müller scale/\% }\end{array}$ \\
\hline \multirow{4}{*}{$3+4$} & 0 & 6 & 6 & 100.0 \\
\cline { 2 - 5 } & 1 & 25 & 25 & 100.0 \\
\cline { 2 - 5 } & 2 & 13 & 12 & 92.3 \\
\cline { 2 - 5 } & 3 & 5 & 5 & 100.0 \\
\cline { 2 - 5 } & Total images & $\mathbf{4 9}$ & $\mathbf{4 8}$ & $\mathbf{9 7 . 9 6}$ \\
\cline { 2 - 5 } & Undefined & $\mathbf{1 0}$ & $\mathbf{N A}$ & NA \\
\hline
\end{tabular}

\begin{tabular}{lll}
\hline Cellulite stage & $\begin{array}{l}\text { Classifier } 3 \\
\text { Range of classifiers' values }(\mathrm{px})\end{array}$ & $\begin{array}{l}\text { Classifier } 4 \\
\text { Range of classifiers' values }(\mathrm{px})\end{array}$ \\
\hline 0 & $<0,0.0136>$ & $<0,25422>$ \\
1 & $<0.0137,0.0771>$ & $<25,423,276,784>$ \\
2 & $<0.0772,0.1471>$ & $<276,785,924,512>$ \\
3 & $<0.1472, \infty>$ & $<924,513, \infty>$ \\
\hline
\end{tabular}

Table 6 Final threshold values of the classifiers for accurate diagnosis of cellulite stages obtained from IR thermography early and personalized monitoring of cellulite development and allow preventive intervention, thus improving women quality of life and self-esteem.

Acknowledgements The study was conducted thanks to the statutory fund from the Polish Ministry of Science and Higher Education (MNISW) which is gratefully acknowledged by the authors of this research.

Open Access This article is distributed under the terms of the Creative Commons Attribution 4.0 International License (http://creative commons.org/licenses/by/4.0/), which permits unrestricted use, distribution, and reproduction in any medium, provided you give appropriate credit to the original author(s) and the source, provide a link to the Creative Commons license, and indicate if changes were made.

\section{References}

1. Janda K, Tomikowska A. Cellulite-causes, prevention, treatment. Ann Acad Med Stetin. 2014;60(1):29-38.

2. Junqueira JP, Alfonso M, de Mello Tucunduva TC, Bussamara Pinheiro MV, Bagatin E. Cellulite: a review. Surg Cosmet Dermatol. 2010;2(3):214-9.

3. Hexsel DM, Dal'Forno T, Hexsel CL. A validated photonumeric cellulite severity scale. JEADV. 2009. https://doi.org/10.1111/j. 1468-3083.2009.03101.x.

4. Cellulite statistics. 2006. http://www.worldvillage.com/cellulitestatistics/. Accessed 3 Jul 2017.

5. Nkengne A, Papillon A, Bertin C. Evaluation of the cellulite using a thermal infra-red camera. Skin Res Technol. 2013;19:231-7.

6. Hexsel D, Blessmann Weber M, Taborda ML, Dal'Forno T, Zechmeister-Prado D. A quality of life measurement for patients with cellulite. Surg Cosmet Dermatol. 2011;3(2):96-101.

7. Terranova F, Berardesca E, Maibach H. Cellulite: nature and aetiopathogenesis. Int J Cosmet Sci. 2006;28:157-67. 
8. de Godoy JMP, de Godoy MFG. Physiopathological hypothesis of cellulite. Open Cardiovasc Med J. 2009;3:96-7.

9. Soares JLM, Miot HA, Sanudo A, Bagatin E. Cellulite: poor correlation between instrumental methods and photograph evaluation for severity classification. Int $\mathbf{J}$ Cosmet Sci. 2015;37:134-40.

10. Tosti A, Hexsel D. Cellulite. In: Tosti A, Hexsel D, editors. Update in cosmetic dermatology. Berlin: Springer; 2013. p. 21-32.

11. Schonvvetter B, Soares JL, Bagatin E. Longitudinal evaluation of manual lymphatic drainage for the treatment of gynoid lipodystrophy. An Bras Dermatol. 2014;89(5):712-8.

12. Schlaudraff K, Kiesling MC, Cszasar N, Schmitz C. Predictability of the individual clinical outcome of extracorporeal shock wave therapy for cellulite. Clin Cosmet Investig Dermatol. 2014; 7:171-83.

13. Mlosek RK, Malinowska S, Dębowska R, Lewandowski M, Nowicki A. The high frequency (HF) ultrasound as a useful imaging technique for the efficacy assessment of different anticellulite treatments. JC DSA. 2013;3:90-8.

14. Enzo E. Cellulite: advances in treatment: facts and controversies. Clin Dermatol. 2013;31:725-30.

15. Rawlings AV. Cellulite and its treatment. Int J Cosmet Sci. 2006;28:175-90.

16. Khan MH, Victor F, Rao B, Sadick NS. Treatment of cellulite: part I. Pathophysiology. J Am Acad Dermatol. 2010;62:361-70.

17. Khan MH, Victor F, Rao B, Sadick NS. Treatment of cellulite: part II. Advances and controversies. J Am Acad Dermatol. 2010;62:373-84.

18. Avram MM. Cellulite: a review of its physiology and treatment. J Cosmet Laser Ther. 2004;6:181-5.

19. Hexsel DM. Body repair. In: Parish LC, Brenner S, Ramos-e Silva M, editors. Women's dermatology-from infancy to maturity. New York: Parthenon Publishing; 2001. p. 586-95.

20. Hexsel D, Dal'Forno TO, Cignachi S. Definition, clinical aspects, associated conditions, and differential diagnosis. In: Goldman MP, Bacci PA, Leibaschoff G, Hexsel D, Angelini F, editors. Cellulite-pathophysiology and treatment. New York: Taylor \& Francis; 2006. p. 7-28.

21. Draelos ZD. The disease of cellulite. J Cosmet Dermatol. 2005;4:221-2.

22. Smith WF. Cellulite treatments: snake oil or skin science. Cosmet Toilet. 1995;110:61-70.

23. Curri SB, Bombardelli E. Local lipodystrophy and distructual microcirculation. Cosmet Toilet. 1994;109:51-65.

24. Curri SB. Cellulite and fatty tissue microcirculation. Cosmet Toilet. 1993;108:51-8.

25. Rossi AB, Vergnanini AL. Cellulite: a review. JEADV. 2000;14:251-62.

26. Nürnberger F, Müller G. So-called cellulite-an invented disease. J Dermatol Surg Oncol. 1978;4(3):221-9.

27. Goldman MP, Hexsel D. Cellulite pathophysiology and treatment. Boca Raton: CRC Press; 2010.
28. Bauer J, Dereń E. Standardization of Infrared thermal imaging in medicine and physiotherapy. Acta Bio Opt Inform Med. 2014;20(1):11-20.

29. Ring F. The historical development of thermometry and thermal imaging in medicine. J Med Eng Technol. 2006;30(4):192-8.

30. Rok T, Rokita E, Tatoń G, Guzik Śliwa T. Thermographic imaging as alternative method in allergy diagnosis. J Therm Anal Calorim. 2016. https://doi.org/10.1007/s10973-016-5676-3.

31. Bauer J, Górecki I, Kohyt M, Migasiewicz A, Podbielska H. The influence of smartphones' operation modes on the superficial temperature distribution in the human auricle region. A smallscale $(\mathrm{n}=20)$ clinical examination. J Therm Anal Calorim. 2018. https://doi.org/10.1007/s10973-018-7047-8.

32. Cholewka A, Kajewska J, Kawecki M, Sieroń-Stołtny K, Stanek A. How to use thermal imaging in venous insufficiency. J Therm Anal Calorim. 2017. https://doi.org/10.1007/s10973-017-6141-7.

33. Cholewka A, Stanek A, Wójcik M, Sieroń-Stołtny K, Drzazga Z. Does local cryotherapy improve thermal diagnosis similar to whole-body cryotherapy in spinal diseases? J Therm Anal Calorim. 2016. https://doi.org/10.1007/s10973-016-5453-3.

34. Miller E, Markiewicz L, Saluk J, Majsterek I. Effect of short-term cryostimulation on antioxidative status and its clinical applications in humans. Eur J Appl Physiol. 2012;112(5):1645-52.

35. Szygula R, Dybek T, Klimek A, Tubek S. Impact of 10 sessions of whole body cryostimulation on cutaneous microcirculation measured by laser doppler flowmetry. J Hum Kinet. 2011;30:75-83.

36. Lubkowska A, Dudzinska W, Bryczkowska I, Dolegowska B. Body composition, lipid profile, adipokine concentration, and antioxidant capacity changes during interventions to treat overweight with exercise programme and whole-body cryostimulation. Oxid Med Cell Longev. 2015. https://doi.org/10.1155/2015/ 803197.

37. Cholewka A, Drzazga Z, Kajewski B, Bogucki R, Wiśniowska B. The thermal imaging of skin body surface due to whole body cryotherapy—preliminary report. Phys Med. 2004;20(1):70-2.

38. Boerner E, Bauer J, Ratajczak B, Dereń E, Podbielska H. Application of thermovision for analysis of superficial temperature distribution changes after physiotherapy-comparison of infrared irradiation and cryotherapy. J Therm Anal Calorim. 2015. https://doi.org/10.1007/s10973-014-4026-6.

39. Boerner E, Podbielska H. Application of thermal imaging to assess the superficial skin temperature distribution after local cryotherapy and ultrasound. J Therm Anal Calorim. 2018. https:// doi.org/10.1007/s10973-017-6772-8.

40. Boerner E, Bauer J, Kuczkowska M, Podbielska H, Ratajczak B. Comparison of the skin surface temperature on the front of thigh after application of combined red-IR radiation and diadynamic currents executed in a different sequence. J Therm Anal Calorim. 2015. https://doi.org/10.1007/s10973-015-4545-9.

41. European Association of Thermology. 2017. http://www.eur opeanthermology.com/cms32/index.php?GUIDELINES. Accessed 1 Dec 2016. 